\title{
Insight, grey matter and cognitive function in first-onset psychosis
}

Kevin D. Morgan, Paola Dazzan, Craig Morgan, Julia Lappin, Gerard Hutchinson, John Suckling,

Paul Fearon, Peter B. Jones, Julian Leff, Robin M. Murray and Anthony S. David

\section{Background}

Several studies have suggested that neuropsychological and structural brain deficits are implicated in poor insight. Few insight studies however have combined neurocognitive and structural neuroanatomical measures.

\section{Aims}

Focusing on the ability to relabel psychotic symptoms as pathological, we examined insight, brain structure and neurocognition in first-onset psychosis.

\section{Method}

Voxel-based magnetic resonance imaging data were acquired from 82 individuals with psychosis and 91 controls assessed with a brief neuropsychological test battery. Insight was measured using the Schedule for the Assessment of Insight.

\section{Results}

The principal analysis showed reduced general neuropsychological function was linked to poor symptom relabelling ability. A subsequent between-psychosis group analysis found those with no symptom relabelling ability had significant global and regional grey matter deficits primarily located at the posterior cingulate gyrus and right precuneus/ cuneus.

\section{Conclusions}

The cingulate gyrus (as part of a midline cortical system) along with right hemisphere regions may be involved in illness and symptom self-appraisal in first-onset psychosis.

\section{Declaration of interest}

None.
Studies examining the relationship between insight and cognition in psychosis have shown small-moderate associations of good insight with both intact frontal-executive functioning and general intellectual abilities. ${ }^{1-3}$ In terms of insight and brain structure, findings suggest an association between poor insight and reduced total brain volume, ${ }^{4,5}$ ventricular enlargement, ${ }^{6}$ frontal lobe atrophy, ${ }^{7}$ reduced frontal lobe volume ${ }^{3,8,9}$ and grey matter deficits in the cingulate gyrus, ${ }^{9,10}$ temporal lobe, ${ }^{9-11}$ parietal lobe ${ }^{11}$ and precuneus. ${ }^{11}$ There is, however, some inconsistency in these findings including cross-study variation in brain location-insight correlates and in some instances a failure to identify any brain deficits associated with poor insight. ${ }^{12-14}$ Table 1 summarises brain structure-insight findings. This inconsistency could arise from the complex nature of insight, which is now regarded as a construct with several overlapping dimensions, ${ }^{15}$ the analysis of which may be further complicated by the use of varying insight assessment methods. A systematic review ${ }^{1}$ and a meta-analysis ${ }^{2}$ have found the ability to identify and attribute the symptoms of psychosis as pathological (symptom relabelling) to be the insight component most closely related to neuropsychological function. In this study we conducted a voxel-based magnetic resonance imaging (MRI) examination of individuals with first-onset psychosis combined with an analysis of cognitive function and hypothesised that neurocognitive deficits would be more closely associated with the capacity to relabel psychotic symptoms as psychopathological rather than a global measure of insight. On the basis of evidence from previous structural neuroimaging ${ }^{7,9}$ and neuropsychological studies ${ }^{1,2}$ of insight, we further hypothesised that the focal point of those deficits would involve a frontal cortical system.

\section{Method}

\section{Sample}

Participants were recruited from a sample of inner-city South London residents enrolled in an epidemiological study of first-onset psychosis (AESOP: Aetiology and Ethnicity in Schizophrenia and Other Psychoses). Details of the AESOP study and the overall methodology have previously been reported. ${ }^{16}$ Insight data were acquired from 137 AESOP study participants. Inclusion criteria for the insight and neurocognition analysis were: age 16-65 years; resident in defined area; presenting consecutively for the first time to local psychiatric services (in-patient and outpatient) between 1997-2000 with symptoms meeting criteria for a functional psychotic illness (ICD-10: 10-19; F20-29; F30-39; psychotic codings $)^{17}$ based on the Schedules for Clinical Assessment in Neuropsychiatry (SCAN) ${ }^{18}$ interview. Exclusion criteria were: head trauma history with $>1 \mathrm{~h}$ unconsciousness; central nervous system disease; poor English fluency; transient psychotic symptoms resulting from acute intoxication (F1x.0, ICD-10) following consumption of a psychoactive substance.

All 137 participants for whom insight data were acquired were asked to have an MRI scan. Thirty-four people refused and four could not be scanned due to safety/medical reasons (e.g. pregnancy). A total of 99 participants gave informed consent and were subsequently scanned. Scan data for 15 of the participants were unusable as a result of poor image acquisition/ motion artefact. A further two scans were excluded after detection of gross brain abnormalities: in one case evidence of significant hydrocephalus and in the other a large frontally located subarachnoid cyst. Thus there were $82(60 \%)$ individuals in the psychosis group who were included in the analysis. These 82 participants had recently presented to psychiatric services for the first time in their lives. Of these, 77 were admitted to hospital at this first presentation, $53(64.6 \%)$ as compulsory patients. Details of their clinical status including medication history are shown in Table 2.

A total of 91 controls were recruited from the same community, using the same exclusion criteria. Evidence of past or present psychosis screened with the Psychosis Screening Questionnaire $^{19}$ was an additional exclusion criterion. We excluded eight MRI control scans (motion artefact, $n=7$; 
Table 1 Previous studies of insight and brain structure ${ }^{a}$

\begin{tabular}{|c|c|c|c|}
\hline Authors & Participants & Main findings & $\begin{array}{l}\text { Insight } \\
\text { measure }\end{array}$ \\
\hline Cooke et al (2008) ${ }^{11}$ & $\begin{array}{l}\text { Schizophrenia, schizoaffective, } \\
\text { out-patients, chronic }(n=52)\end{array}$ & $\begin{array}{l}\text { Insight impairment associated with reduced grey matter volume in left } \\
\text { precuneus and left superior-middle temporal, right superior temporal, } \\
\text { right inferior temporal and right lateral parietal gyri. }\end{array}$ & SAI-E/BIS \\
\hline Sapara et al (2007) ${ }^{9}$ & $\begin{array}{l}\text { Schizophrenia, chronic, out-patients } \\
(n=28)\end{array}$ & Smaller prefrontal grey matter volume and poor insight association & SAI-E \\
\hline Bassitt et al (2006) ${ }^{12}$ & Schizophrenia $(n=50)$ & $\begin{array}{l}\text { No association between insight impairment and reduced grey or white } \\
\text { matter volumes in the prefrontal region or in any other brain areas }\end{array}$ & SUMD \\
\hline Shad et al (2006) ${ }^{3}$ & Schizophrenia, first episode $(n=14)$ & $\begin{array}{l}\text { Reduced symptom awareness and poor symptom attribution associated with } \\
\text { reduced right dorsolateral prefrontal cortex volume and reduced right orbital } \\
\text { prefrontal cortex volume respectively }\end{array}$ & SUMD \\
\hline McEvoy et al $(2006)^{5}$ & Schizophrenia, first episode $(n=226)$ & Larger brain volumes associated with more insight & ITAQ \\
\hline Haa et al $(2004)^{10}$ & Schizophrenia, out-patients $(n=35)$ & $\begin{array}{l}\text { Grey matter reductions in left posterior and right anterior cingulate gyrus } \\
\text { and bilateral inferior temporal regions associated with poor insight }\end{array}$ & PANSS \\
\hline Rossell et al $(2003)^{13}$ & $\begin{array}{l}\text { Individuals with schizophrenia } \\
\text { (males), mixed illness duration }(n=78)\end{array}$ & $\begin{array}{l}\text { No association between insight and whole brain, total white matter and total } \\
\text { grey matter volumes }\end{array}$ & SAI-E \\
\hline Flashman et al (2001) & Schizophrenia $(n=15)$ & $\begin{array}{l}\text { Unawareness of illness and symptom misattribution associated with reduced } \\
\text { middle frontal gyrus and reduced superior frontal gyrus volume respectively }\end{array}$ & SUMD \\
\hline Laroi et al (2000) & Schizophrenia $(n=20)$ & Frontal lobe atrophy associated with poor insight & SUMD \\
\hline Flashman et al (2000) $^{4}$ & Schizophrenia spectrum $(n=30)$ & Reduced whole brain volume associated with poor insight & SUMD \\
\hline David et al (1995) ${ }^{14}$ & Mixed psychosis $(n=128)$ & No association between insight and ventricular volume & PANSS \\
\hline Takai et al (1992) ${ }^{6}$ & Schizophrenia, chronic $(n=22)$ & Ventricular enlargement associated with poor insight & PANSS \\
\hline
\end{tabular}

\begin{tabular}{|c|c|c|c|c|}
\hline & $\begin{array}{l}\text { Psychosis group } \\
\qquad(n=82)\end{array}$ & $\begin{array}{l}\text { Control group } \\
\qquad(n=91)\end{array}$ & Test statistic & $P$ \\
\hline Age, years: mean (s.d.) & $27.15(7.58)$ & $30.05(8.65)$ & $t=-2.34$ & 0.02 \\
\hline Education, years: mean (s.d.) & $12.95(2.44)$ & $11.80(16.97)$ & $t=0.60$ & 0.54 \\
\hline Premorbid IQ (National Adult Reading Test), mean (s.d.) & $96.4(16.0)$ & $108.1(11.5)$ & $F=23.1^{a}$ & $<0.001$ \\
\hline Total grey matter, ml: mean (s.d.) & $574.41(57.14)$ & $589.55(56.60)$ & $F=5.64^{\mathrm{a}}$ & 0.02 \\
\hline Total ventricular volume, ml: mean (s.d.) & $17.20(8.61)$ & $16.1(8.47)$ & $F=3.67^{b}$ & 0.06 \\
\hline $\begin{array}{l}\text { Parental socioeconomic status, } n \text { (\%) } \\
\text { Managerial/professional } \\
\text { Intermediate (e.g. clerical, sales, skilled non-manual) } \\
\text { Working (e.g. unskilled, routine occupations) }\end{array}$ & $\begin{array}{l}26(31.7) \\
19(23.2) \\
37(45.1)\end{array}$ & $\begin{array}{l}34(37.4) \\
30(33.0) \\
25(27.5)\end{array}$ & $\chi^{2}=7.41$ & 0.06 \\
\hline Gender, female/male: $n$ (\%) & $32 / 50(39.0 / 61.0)$ & $37 / 54(40.7 / 59.3)$ & $\chi^{2}=0.48$ & 0.8 \\
\hline Ethnicity, White British/not White British: $n$ (\%) & $30 / 52(36.6 / 63.4)$ & $42 / 49(46.2 / 53.8)$ & $\chi^{2}=2.58$ & 0.11 \\
\hline Handedness, right/left: ${ }^{\circ} n(\%)$ & $76 / 6(92.7 / 7.3)$ & $71 / 12(85.5 / 14.5)$ & $\chi^{2}=2.14$ & 0.14 \\
\hline $\begin{array}{l}\text { Diagnosis, } n \text { (\%) } \\
\text { Schizophrenia } \\
\text { schizoaffective } \\
\text { Bipolar disorder } \\
\text { Depressive psychosis } \\
\text { Other psychosis }\end{array}$ & $\begin{array}{l}39(47.6) \\
6(7.3) \\
17(20.7) \\
10(12.2) \\
10(12.2)\end{array}$ & & & \\
\hline $\begin{array}{l}\text { Admission status, } n(\%) \\
\text { Informald }^{d} \\
\text { Compulsory }^{\text {com }}\end{array}$ & $\begin{array}{l}29(35.4) \\
53(64.6)\end{array}$ & & & \\
\hline $\begin{array}{l}\text { Type of antipsychotic, } n(\%) \\
\text { Typical } \\
\text { Atypical } \\
\text { Mixed } \\
\text { None }\end{array}$ & $\begin{array}{l}21(23.2) \\
19(23.2) \\
29(35.3) \\
13(15.9)\end{array}$ & & & \\
\hline Duration of antipsychotic treatment, weeks: mean (s.d.) & $5.70(6.7)$ & & & \\
\hline Interval between first presentation and MRI scan/assessment, weeks: mean (s.d.) & $13.06(13.1)$ & & & \\
\hline Total symptom ratings, mean (s.d.) & $31.02(17.7)$ & & & \\
\hline $\begin{array}{l}\text { MRI, magnetic resonance imaging. } \\
\text { a. ANCOVA, controlling for age, } 3 \text { people in the psychosis group and } 11 \text { in the control group did } \\
\text { b. Analysis based on lateral ventricle to whole brain volume ratio. } \\
\text { c. Handedness rated according to hand for writing. } \\
\text { d. Five people in the psychosis group treated on out-patient basis only. }\end{array}$ & complete the National & lt Reading Test. & & \\
\hline
\end{tabular}


suspected hydrocephalus, $n=1$ ). As insight-cognition associations cannot be derived from a non-clinical sample, the purpose of including healthy controls was to compare global grey matter volume, ventricular volume and general intellectual functioning (measured with the National Adult Reading Test (NART) ${ }^{20}$ with the psychosis group. A detailed MRI analysis comparing AESOP patient-control brain structure has been reported earlier. ${ }^{21}$

\section{Assessments}

\section{Clinical assessments}

Individuals in the psychosis group were interviewed using the SCAN. We made ICD-10 diagnoses in consensus meetings with senior clinicians (R.M.M. or J.L.), using SCAN information and clinical notes. Total symptomatology was scored using an algorithm that summed the SCAN's individual item scores. ${ }^{22}$

\section{Insight}

Insight ratings were made from semi-structured interviews using the Schedule for the Assessment of Insight - Expanded version (SAI-E). ${ }^{23}$ The SAI-E is an 11-item semi-structured interview that allows for the measure of symptom relabelling, overall illness awareness and treatment adherence. Symptom relabelling ratings are based on two items relating to: awareness of most prominent psychotic symptoms; and explanation of the presence of each prominent symptom. For both items the response for each symptom was scored between 0 (complete lack of awareness) and 4 (full awareness). The individual symptom ratings were averaged yielding a score between $0-4$. The two item scores were combined so that the maximum possible (full) symptom relabelling score is 8 .

A principal components factor analysis (with varimax rotation) of the insight data yielded three factors that accounted for $66.5 \%$ of the variance (lowest eigenvalue 1.05). ${ }^{24}$ This finding corresponds directly with the three-component model of insight described above. Ratings of total insight consist of the combined SAI-E scores (items 1-11).

\section{Interrater reliability}

Only SCAN-trained researchers administered the SAI-E interviews. Two measures were implemented to ensure good interrater reliability. First, one-to-one SAI-E training sessions were conducted. Second, all SAI-E interviewers scored a battery of 16 completed interviews prepared specifically to assess interrater reliability. These schedules are reproductions of real interviews with a verbatim record of the individuals' responses and the scoring sections left blank. Intraclass correlation coefficients for the total SAI-E scores between the raters ranged from 0.92 to $0.98(P<0.001)$.

\section{Cognitive tests}

The psychosis group completed a cognitive test battery of selected items to assess premorbid intelligence, current IQ, psychomotor speed, spatial ability, verbal fluency, set shifting, auditory working memory, verbal and non-verbal memory (Table 3). Trained researchers administered the battery and scored the assessments (masked to SAI-E scores). The control group completed the NART. $^{20}$

\section{Structural magnetic resonance image acquisition and processing}

Scans were acquired with a GE Signa 1.5-T system, at the Maudsley Hospital, London. Contiguous, interleaved protondensity and $T_{2}$-weighted $3 \mathrm{~mm}$ thick coronal plane dual-echo images were acquired, providing whole brain coverage: repetition time $(\mathrm{TR})=4000 \mathrm{~ms}$ and effective echo times of $20 \mathrm{~ms}$ and $85 \mathrm{~ms}$ were used with 8 -echo train length. Matrix size was $256 \times 192$, collected from a rectangular field-of-view of $22 \mathrm{~cm} \times 16.5 \mathrm{~cm}$, giving an in-plane resolution of $0.859 \mathrm{~mm}$. Total acquisition time was $10 \mathrm{~min}, 12 \mathrm{~s}$.

Segmentation and registration methods for each fast-spin echo data-set are described in detail elsewhere. ${ }^{32,33}$ Briefly, participant masks were generated to identify neural tissue. Extra-cerebral tissues were removed initially, using an automated algorithm. Manually editing the skull-stripped images was necessary only to remove brainstem and cerebellum from the cerebral hemispheres and diencephalon. The probability of each intracerebral voxel belonging to each of four possible tissue classes (grey matter, white matter, cerebrospinal fluid (CSF) or dura/vasculature) was estimated with a modified fuzzy clustering algorithm. ${ }^{33}$ This type of segmentation assigns for each voxel a value in the range $0-1$ indicating the fraction of the voxel comprised by each tissue type (e.g. a grey matter value of 0.7 means $70 \%$ of tissue represented by that voxel is grey matter; therefore the value indicates the proportion of the voxel occupied by grey matter). Total grey tissue volume was calculated at this stage of the analysis.

The construction of the sample's template image is described elsewhere. ${ }^{21}$ In summary, a template image was constructed using the AFNI (Analysis of Functional Neuroimages) Unix-based program developed at the Medical College of Wisconsin (www.biophysics.mcw.edu), from 6 proton-density images acquired from six healthy, controls and then averaging these images.

\section{Ventricular volume}

Additional masks were generated per participant by tracing around the lateral and third ventricles in native space, in every

\begin{tabular}{|c|c|c|}
\hline Domain & Test & Author \\
\hline General intelligence & $\begin{array}{l}\text { National Adult Reading Test (NART) } \\
\text { Wechsler Adult Intelligence Scale - Revised (WAIS-R) } \\
\text { Ravens Coloured Progressive Matrices (Ravens CPM) }\end{array}$ & $\begin{array}{l}\text { Nelson \& Willison, } 1991^{20} \\
\text { Wechsler, } 1981^{25} \\
\text { Ravens, } 1974^{26}\end{array}$ \\
\hline Verbal memory & $\begin{array}{l}\text { Auditory Verbal Learning Test - Immediate recall (AVLT-IR) (Item 1) } \\
\text { Auditory Verbal Learning Test - Verbal learning (AVLT-VL) (Items 1-5) }\end{array}$ & Rey, $1964^{27}$ \\
\hline Non-verbal memory & Visual reproduction - Immediate recall (WMS-IR) & Wechsler, $1987^{28}$ \\
\hline Working memory & Letter-Number Span Test - Working memory (LNS-WM) & Gold et al, $1997^{29}$ \\
\hline Verbal fluency & Verbal fluency Controlled Oral Word Association Test (FAS) & Yeudall et al, $1986^{30}$ \\
\hline Set shifting & Trails B-A & Reitan, $1958^{31}$ \\
\hline Psychomotor speed & Trails A & Reitan, $1958^{31}$ \\
\hline
\end{tabular}


slice in which they were visible. Tracing was performed masked to age, gender and clinical status. Within the masked area, CSF volume was calculated using the data generated from the previously described modified fuzzy clustering algorithm.

\section{Statistical analysis}

\section{Psychosis group $v$. control group}

A between-group ANCOVA (controlling for age) comparing the psychosis group and the control group was performed to evaluate whether the whole psychosis group (irrespective of insight levels) was characterised by deficits in total grey matter volume, excess ventricular volume and poor general intellectual functioning.

\section{Insight, global grey matter and ventricular volume}

Total tissue volumes were generated prior to the registration of the images into standard space. We calculated correlation coefficients (age partialled) to investigate total grey matter volume and ventricular volume associations (controlling for whole brain volume) with the measures of symptom relabelling and total insight within the whole psychosis group sample.

\section{Insight and regional grey matter volume}

Within-group analyses of associations between insight scores and regional grey matter volume were estimated by fitting an ANCOVA model at each intracerebral voxel in standard space covarying for age and total grey matter volume. Permutation testing was used to assess statistical significance and regional relationships were tested at voxel cluster level. ${ }^{32}$ Given that structural brain changes are likely to extend over a number of contiguous voxels, test statistics incorporating spatial information, such as three-dimensional (3D) cluster mass (the sum of suprathreshold voxel statistics), are generally more powerful than other possible test statistics informed only by single voxel data. We set the statistical threshold for cluster significance in all analyses so that the expected number of false-positive clusters $(P$-value $\times$ number of tests) was $<1$ false positive.

\section{Insight and cognitive function}

We calculated correlation coefficients (age partialled) to investigate associations of performance on each of the cognitive takes with the obtained measures of insight within the whole psychosis group sample.

\section{Analysis of symptom relabelling}

Additional between-group analyses comparing the psychosis group with no symptom relabelling ability to those with at least partial symptom relabelling ability were performed. These analyses examined between-group differences in total grey matter volume, ventricular volume, regional grey matter volume and cognitive test performance using ANCOVA (age partialled). The procedure for analysis of regional differences in grey matter volume was carried out by fitting an ANCOVA model at each intracerebral voxel in standard space and conducting permutation testing as described above for the within-group analysis.

Linear regression was performed to estimate the extent to which the structural brain abnormalities and/or cognitive differences identified in the series of ANCOVAs described above contributed to the variance in ratings for symptom relabelling. These regression analyses controlled for the potentially confounding factors of age and total grey matter volume.
The SPSS (Version 14.0 for Windows) was used to carry out the statistical tests. All participants gave their informed consent to take part in the study. Ethical approval for the study was granted by the South London and Maudsley NHS Trust.

\section{Results}

\section{Psychosis group v. control group}

The participants in the psychosis group were significantly older than those in the control group $(30.1$ (s.d. $=8.7)$ years $v .27 .2$ (s.d.=7.6) years, $t=2.34$, d.f. $=171, \quad P=0.02)$ and scored significantly lower on the NART $(96.4 \quad($ s.d.=16.0) $\quad$ v. 108.1 (s.d.=11.5), $F=23.1$, d.f. $=1155, P<0.001) . T$-tests and chisquared analyses showed no significant psychosis group-control group differences for gender, handedness, parental socioeconomic status and ethnicity. Total grey tissue volume in the psychosis group was $2.5 \%$ smaller than in the control group $(574.81 \mathrm{ml}$ (s.d.=57.14) $\quad v .589 .55 \mathrm{ml} \quad($ s.d. $=56.60) \quad F=5.64, \quad$ d.f. $=169$, $P=0.02$ ). Lateral ventricular volume was $6.4 \%$ larger in the psychosis group $(17.2 \mathrm{ml}($ s.d. = 8.61) v. $16.1 \mathrm{ml}($ s.d.=8.47)), with the psychosis group having a larger lateral ventricle to brain volume ratio than the control group that bordered on statistical significance $(F=3.66$, d.f. $=166, P=0.06)$ (Table 2).

\section{Within-psychois group analysis: insight, global grey matter, regional grey matter and ventricular volume}

There were not significant correlations between symptom relabelling scores and volumetric measures for total grey matter, regional grey matter or lateral ventricular volume. Similarly, there were no significant associations between scores for total insight and the same neuroanatomical measures. There was, however, a correlation between lower total insight ratings and reduced total grey matter volume (age partialled) that reached borderline significance $(r=0.23, P=0.06)$.

\section{Insight and cognitive function (correlations - age partialled)}

Reduced symptom relabelling correlated significantly with poorer: NART IQ $(r=0.27, P=0.03)$; full-scale IQ (FSIQ) $(r=0.33$, $P=0.01)$; performance IQ (PIQ) $(r=0.36, P<0.01)$; verbal learning $(r=0.30, P=0.02)$; and Trails A speed $(r=-0.25$, $P=0.04)$. Reduced total insight correlated significantly with poorer: NART IQ $(r=0.32, P=0.02)$, FSIQ $(r=0.27, P=0.02)$; PIQ ( $r=0.35, P<0.01)$; verbal learning $(r=0.46, P<0.001)$; and Letter-Number Span (LNS)-Working memory $(r=0.32$, $P=0.02$ ). After adjusting with Bonferroni correction for multiple comparisons only the following correlations remained significant: symptom relabelling with PIQ; total insight with PIQ; and total insight with verbal learning.

\section{Between-psychosis group analysis}

An analysis of the obtained insight scores revealed that 20/82 (24.4\%) of the psychosis group (the first quartile) scored zero on the symptom relabelling component of insight (Fig. 1). We considered that neurocognitive deficts may be most evident in those individuals where there is a total absence of any capacity to question the presence of psychotic symptoms as pathological. Therefore, a between-group analysis of the 20 participants with no symptom relabelling ability and the 62 participants with at least some symptom relabelling ability was performed to compare global and regional grey matter volume, ventricular volume and cognitive performance. Chi-squared tests and independent 


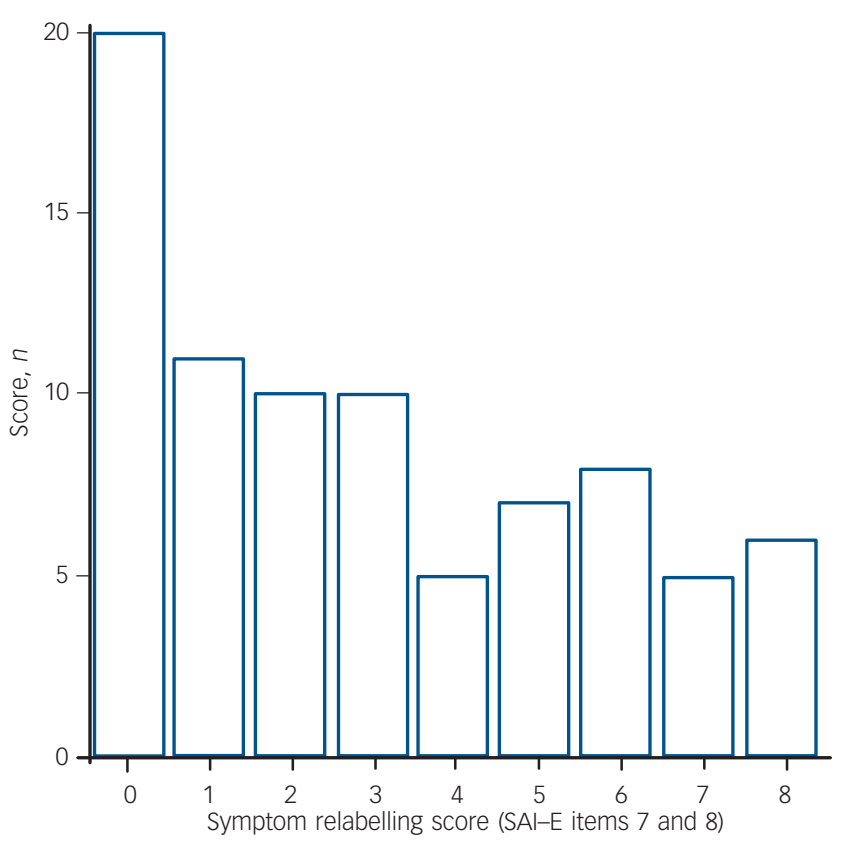

Fig. 1 Distribution of symptom relabelling scores $(n=82)$.

SAI-E, Schedule for the Assessment of Insight - Expanded version.

samples $t$-tests revealed no significant between-group differences for gender, total symptoms, diagnosis (schizophrenia $v$. other psychosis), years of education and handedness. The mean age of the no symptom relabelling ability subgroup was higher than that of the subgroup with at least some symptom relabelling scores (30.6 v. 26.0 years, $t=-2.41$, d.f. $=80, P=0.02$ ). The distribution of scores for total insight was not comparable with that of symptom relabelling, i.e. no participants scored $<1$ for total insight, therefore a similar post hoc analysis for total insight was not performed.

\section{Symptom relabelling between-group analysis: global grey matter, regional grey matter and ventricular volume}

Total grey tissue volume in the no symptom relabelling subgroup was $6.7 \%$ lower than in the subgroup with at least some symptom relabelling ablity (ANCOVA controlling for age: $F=6.77$, d.f. $=78$, $P=0.01)$. A significant reduction in grey tissue volume was identified in the no symptom relabelling subgroup in the following five spatially extensive $3 \mathrm{D}$ voxel clusters:

(a) left hemisphere cluster centred on the insula;

(b) right hemisphere cluster extending from the putamen to the superior temporal gyrus and precentral gyrus;

(c) left hemisphere cluster extending from the precentral gyrus to the superior temporal gyrus;

(d) bilateral cluster extending posteriorly from the posterior cingulate gyrus to the superior parietal lobe/precuneus;

(e) right hemisphere cluster extending posteriorly from the precuneus through the cuneus to the medial occipital gyrus.

There were no significant between-group differences in ventricular volumes (Tables 4 and 5 and online Fig. DS1). To examine the potential effect of IQ on the between-group differences in regional grey matter volumes, a further ANCOVA was conducted controlling for FSIQ. In this additional analysis, the between-group differences in all five regions described above remained significant $(P<0.001)$.

\section{Symptom relabelling between-group analysis: cognition}

The ANCOVA (controlling for age) showed that the subgrop with no symptom relabelling ability scored significantly lower than those with some symptom relabelling ability on FSIQ $(F=8.75$, d.f. $=77, P<0.01)$; verbal IQ (VIQ) $(F=5.90$, d.f. $=77, P=0.02)$, PIQ $(F=8.30$, d.f. $=79, P<0.01)$; verbal fluency $(F=6.60$, d.f. $=75, P<0.05)$; Trails A $(F=11.59$, d.f. $=75, P<0.01)$; and verbal learning $(F=3.83$, d.f. $=74, P=0.05)$. There were no other significant differences for cognitive performance (Table 4).

A stepwise linear regression controlling for diagnostic status revealed significant effects for right hemisphere cuneus grey matter deficits and PIQ scores accounting for $31 \%$ of the variance in symptom relabelling $\left(R^{2}=0.30, P<0.001\right)$. Reduced grey matter in those clusters and lower PIQ scores were associated with lower symptom relabelling scores. No other factors were associated with symptom relabelling. The beta (standardised) coefficients indicate right hemisphere grey matter cuneus deficits ( $\beta=0.413, P<0.001)$ are more predictive of poor symptom relabelling than lower PIQ scores $(\beta=0.274, P<0.01)$ (Tables 4 and 5 and online Fig. DS1).

\section{Discussion}

\section{Psychosis group $\boldsymbol{v}$. control group}

The psychosis group-control group comparisons indicated global grey matter deficits, ventricular enlargement and lower general intellectual functioning in the group with psychosis. These structural and functional abnormalities are consistent with the findings of several cognitive and MRI studies of individuals with first-episode, intermediate and chronic psychosis. ${ }^{34,35}$

\section{Within-psychosis group analysis of insight}

Contrary to our predictions, the main analyses of symptom relabelling across the whole range of scores found no significant associations with structural brain measures, although a correlation between global grey matter volume and total insight scores that approached statistical significance $(P=0.06)$ was identified. As expected and also in agreement with previous findings, ${ }^{1,2}$ the analysis of cognitive performance provided evidence that both symptom relabelling and insight in general are at least partly dependent on good overall cognitive function.

\section{Between-psychosis group analysis of insight}

Scrutiny of the insight scale revealed that there was a bimodal distribution of scores for symptom relabelling. Twenty people in the psychosis group (24.4\%) scored zero for insight relabelling, i.e. showing no capacity to identify psychotic symptoms as pathological (Fig. 1). Further to the planned analysis, we considered that in terms of symptom relabelling ability, this subgroup of participants may more closely resemble people with neurological conditions experiencing anosognosia and that consequently more evidence of neuroanatomical and neuropsychological deficits would be found in this group. This prediction was based on the rationale that neurocognitive deficits would be most evident in indivdiuals where there appears to be no capacity to hold in mind, question and consider alternative (non-psychopathological) explanations for symptoms such as 
Table 4 Comparison of brain structure and cognitive function between patients with low or moderate-high insight levels

\begin{tabular}{|c|c|c|c|c|c|c|c|}
\hline & \multicolumn{4}{|c|}{ Symptom relabelling ability } & \multirow[b]{3}{*}{$B$} & \multirow[b]{3}{*}{$\beta$} & \multirow[b]{3}{*}{$P$} \\
\hline & \multicolumn{2}{|c|}{ No symptom relabelling } & \multicolumn{2}{|c|}{ Some symptom relabelling } & & & \\
\hline & $n$ & Mean (s.d.) & $n$ & Mean (s.d.) & & & \\
\hline \multicolumn{8}{|l|}{ Brain structure } \\
\hline \multicolumn{8}{|l|}{ Volume, $\mathrm{ml}$} \\
\hline Total grey & 20 & $545.0(5.5)$ & 62 & $583.9(57.1)$ & & & 0.01 \\
\hline Lateral ventricles ${ }^{a}$ & 20 & $16.9(6.3)$ & 62 & $18.0(13.8)$ & & & NS \\
\hline \multicolumn{8}{|l|}{ Cluster volume, ml } \\
\hline Posterior cingulate cyrus (bilateral) & 20 & $1.4(0.2)$ & 62 & $1.7(0.2)$ & & & 0.002 \\
\hline Insula (left hemisphere) & 20 & $0.9(0.1)$ & 62 & $1.1(0.9)$ & & & 0.002 \\
\hline Superior temporal gyrus (right hemisphere) & 20 & $1.6(0.2)$ & 62 & $1.8(0.1)$ & & & 0.002 \\
\hline Superior temporal gyrus (left hemisphere) & 20 & $0.8(0.1)$ & 62 & $1.0(0.1)$ & & & 0.002 \\
\hline Cuneus (right hemisphere) & 20 & $0.5(0.1)$ & 62 & $0.6(0.1)$ & & & 0.002 \\
\hline \multicolumn{8}{|l|}{ Cognitive test $\mathrm{t}^{\mathrm{b}}$} \\
\hline National Adult Reading Test & 19 & $90.7(14.5)$ & 60 & $98.2(15.9)$ & & & 0.07 \\
\hline Performance IQ & 19 & $77.6(11.6)$ & 62 & $91.7(20.3)$ & & & $<0.01$ \\
\hline Verbal IQ & 18 & $82.9(10.8)$ & 60 & $93.2(17.4)$ & & & $<0.05$ \\
\hline Ravens Coloured Progressive Matrices & 18 & $28.9(4.1)$ & 56 & $31.6(4.2)$ & & & $<0.05$ \\
\hline Auditory Verbal Learning Test - Immediate recall & 18 & $5.4(1.2)$ & 58 & $6.50(2.19)$ & & & 0.05 \\
\hline Auditory Verbal Learning Test - Verbal learning & 18 & $42.28(9.1)$ & 58 & $47.7(10.5)$ & & & 0.05 \\
\hline Wechsler Memory Scale - Visual reproduction & 17 & $9.2(2.7)$ & 52 & $10.5(1.4)$ & & & NS \\
\hline Verbal Fluency Controlled Oral Word Association Test & 18 & $9.6(14.7)$ & 59 & $62.0(18.8)$ & & & $<0.05$ \\
\hline Letter-Number Span Test & 17 & $11.4(2.9)$ & 58 & $13.2(3.7)$ & & & 0.07 \\
\hline Trails $A^{b}$ & 18 & $40.6(18.0)$ & 59 & $66.0(43.4)$ & & & 0.001 \\
\hline Trails $B-A^{b}$ & 18 & $55.7(42.1)$ & 58 & $79.8(46.9)$ & & & $<0.05$ \\
\hline \multicolumn{8}{|l|}{ Regression analysis $^{\mathrm{c}}$} \\
\hline \multicolumn{8}{|l|}{ Predictor } \\
\hline Cuneus (right hemisphere) & & & & & 12.9 & 0.4 & $<0.001$ \\
\hline Performance IQ & & & & & 0.1 & 0.3 & $<0.01$ \\
\hline \multicolumn{8}{|c|}{$\begin{array}{l}\text { NS, not significant. } \\
\text { a. Analysis based on lateral ventricle to whole brain volume ratio. } \\
\text { b. The distribution of completion times for Trails } \mathrm{A} \text { and Trails B-A were positively skewed. For this analysis a logarithmic transformation (log value base e) was performed on both } \\
\text { Trails } \mathrm{A} \text { and } \mathrm{B}-\mathrm{A} \text { data. Means and s.d. shown in seconds. } \\
\text { c. } n=82, R^{2}=0.30 \text {, adjusted } R^{2}=0.28 \text {, estimated s.e. }=2.36 \text {. }\end{array}$} \\
\hline
\end{tabular}

\begin{tabular}{|c|c|c|c|c|}
\hline \multicolumn{3}{|c|}{ 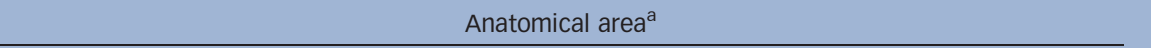 } & \multirow{2}{*}{$\begin{array}{l}\text { Number of voxels } \\
\text { in cluster }\end{array}$} & \multirow{2}{*}{$\begin{array}{l}\text { Location of cluster centre } \\
\qquad x, y, z\end{array}$} \\
\hline Centroid & Anterior limit & Posterior limit & & \\
\hline Left insula (43) & Insula (45) & Insula (43) & 390 & $-38,4,7$ \\
\hline $\begin{array}{l}\text { Right superior temporal gyrus } \\
\text { (22)/precentral gyrus (4) }\end{array}$ & Putamen (n/a) & Superior temporal gyrus (22) & 273 & $23,7,2$ \\
\hline Left superior temporal gyrus (41) & Precentral gyrus (4) & Superior temporal gyrus (41) & 300 & $-43,28,15$ \\
\hline Bilaterial posterior cingulate gyrus (31) & Posterior cingulate gyrus (31) & Superior parietal lobe/precuneus (7) & 533 & $0,-48,40$ \\
\hline Right cuneus (18) & Precuneus (7) & Medial/lateral occipital gyrus (19) & 273 & $7,-79,24$ \\
\hline
\end{tabular}

hallucinations and delusions. Thus we compared those participants with no symptom relabelling ability with those with at least some relabelling ability. The findings from the analyses of cognitive function supported this rationale. Whereas deficits were seen on tests of working memory, processing speed and verbal fluency, there was evidence of a reduction in general intellectual abilities in both the verbal but also non-verbal domains, the latter traditionally linked to right hemisphere functions.

In terms of brain structure we found significantly reduced global grey matter volume in the subgroup with no symptom relabelling ability. In the regional analysis we found reduced grey matter in the left posterior cingulate cyrus, the right precuneus and the cuneus, with the latter region emerging as a significant predictor of poor symptom relabelling in the regression analysis.
The finding in relation to the posterior cingulate gyrus is in line with a previous voxel-based morphometry study ${ }^{10}$ that found a correlation between severity of lack of insight in schizophrenia and reduced left posterior cingulate gyrus volume at the same location (Brodmann 31). In another voxel-based morphometry analysis of people with schizphrenia, ${ }^{11}$ left precuneus grey matter reductions were also shown to be associated with poor insight. Elsewhere, however, comparatively few studies have focused on the function and dysfunction of posterior medial cortices in general or in schizophrenia. However, of possible relevance to developing an understanding of the neuroanatomical substrates of insight, the precuneus has been shown to be involved in the representation (monitoring) of the world around us. ${ }^{36}$ Dysfunction of the right parietal lobe has also been highlighted as underlying delusions of alien control through faulty self-monitoring ${ }^{37}$ and 
the condition of anosognosia. ${ }^{38}$ Recent functional imaging studies have shown a consistent localisation of self-appraisal processes to the midline cortical structures (including the posterior cingulate gyrus) in healthy volunteers. ${ }^{39}$ Consistent with this, the posterior cingulate gyrus was activated during self-appraisal in a study of elderly people with cognitive impairments. ${ }^{40}$

We also found grey matter insula deficits to be associated with an absence of symptom relabelling. Although no previous insightbrain structure studies have reported insula abnormalities, findings from functional imaging studies suggest that the insula is involved in self-monitoring, ${ }^{41}$ the ability to discriminate between other-person generated actions and self-generated actions $^{42}$ and in the mental representation of internal states, ${ }^{42}$ all of which appear relevant to insight. In respect of temporal lobe-insight associations, reduced grey matter reductions have previously been shown to correlate with poor symptom relabelling (right superior temporal gyrus) and poor illness awareness (left-middle temporal region). ${ }^{11}$ In our study, superior temporal gyrus grey matter deficits (left and right hemisphere) were also found in the subgroup with no symptom relabelling ability. Based on structural imaging findings the superior temporal gyrus has long been implicated in key psychotic symptoms, notably auditory hallucinations, ${ }^{43}$ a phenomenon thought to involve defective monitoring and self-attribution of inner-speech. ${ }^{44}$ This pattern of MRI abnormalities leads us to speculate that insight into psychosis involves midline cortical and right posterior hemisphere regions underlying illness awareness and self-appraisal processes in general, plus lateralised symptom-specific regions connected more directly to the origin of the symptoms themselves, i.e. superior temporal gyrus in relation to auditory hallucinations and parietal cortex in passivity. Such a model is similar to that advanced for anosognosia with general and symptom specific modules of awareness. $^{45}$

\section{Main findings}

In this study of people with first-onset psychosis, performance on a range of cognitive tasks was impaired in those with poor symptom relabelling ability and poor global insight suggesting that a good level of general cognitive functioning is necessary for good insight into psychosis rather than a specific system such as one drawing on frontal-executive resources. In those with the lowest levels of symptom relabelling ability there was evidence of both global and regional cortical deficits. Our data point to a midline and right hemisphere cortical system, normally involved in self-appraisal, being implicated in symptom appraisal, with temporal and parietal regions also involved, perhaps reflecting symptom-specific elements of psychiatric insight.

\section{Study limitations}

The inclusion of additional neuropsychological tests more sensitive to disturbances in executive function (e.g. the Wisconsin Card Sorting Task) or those aimed at dissecting the cognitive processes underpinning self-appraisal would have been desirable and could potentially have shed more light on the complex relationship between neurocognition and the self-appraisal of symptoms. The study's findings are also limited by the fact that the association with symptom relabelling only emerged strongly when the phenomenon was considered categorically rather than as a dimension. From a diagnostic perspective it was not our primary concern to investigate whether mechanisms for insight into psychotic symptoms differ across conditions. Diagnostic status was however examined in the linear regression analysis and did not emerge as a significant factor in the associations found between symptom relabelling and the measures of regional grey matter and cognition. It would have been informative to also consider diagnostic status in the between-group analyses; however, the size of the group numbers do not provide sufficient statistical power to perform separate analyses based on diagnostic status. Our findings should therefore be regarded as tentative and as providing a basis for future investigations of insight in the psychoses. In this respect, a longitudinal analysis of both insight and neurocognitive status over time would be revealing given the cross-sectional nature of our study. Further evidence that neurocognitive deficits underpin the most severe incapacity to identifying psychotic states as pathological may be of importance clinically in setting a limit upon expectations for recovery.

Kevin D. Morgan, PhD, Paola Dazzan, MBChB, MSC, MRCPsych, Craig Morgan, PhD, Julia Lappin, MBChB, MSC, Gerard Hutchinson, MD, MRCPsych, Institute of Psychiatry, Division of Psychological Medicine, King's College London; John Suckling PhD, Institute of Psychiatry, Department of Neurology, King's College London; Paul Fearon, MBChB, MSC, MRCPsych, Institute of Psychiatry, Division of Psychological Medicine, King's College London; Peter B. Jones, MBChB, PhD, MRCPsych, University of Cambridge, Department of Psychiatry, Addenbrooke's Hospital, Cambridge; Julian Leff, MBChB, PhD, FRCPsych, Robin M. Murray, MBChB, MPhil, FRCPsych, Anthony S. David, MD, RCPsych, Institute of Psychiatry, Division of Psychological Medicine, King's College London, UK

Correspondence: Kevin D. Morgan, PhD, Department of Psychology, University of Westminster, 309 Regent Street, London W1B 2UW, UK. Email: k.d.morgan@westminster.ac.uk

First received 20 Jul 2009, final revision 14 Apr 2010, accepted 27 Apr 2010

\section{Funding}

The AESOP study was funded by the Medical Research Council (UK) and the Stanley Medical Research Institute (USA). We would also like to thank the NIHR Biomedical Research Centre for Mental Health for their support.

\section{References}

1 Morgan KD, David A. Neuropsychological studies of insight in patients with psychotic disorders. In Insight and Psychosis (eds X Amador, A David): 177-196. Oxford University Press, 2004.

2 Aleman A, Agrawal N, Morgan KD, David AS. Insight in psychosis and neuropsychological function. Meta-analysis. Br J Psychiatry 2006; 189: 204-12.

3 Shad MU, Muddasani S, Keshavan MS. Prefrontal subregions and dimensions of insight in first-episode schizophrenia - a pilot study. Psychiatry Res 2006; 146: $35-42$.

4 Flashman LA, McAllister TW, Andreasen NC, Saykin AJ. Smaller brain size associated with unawareness of illness in patients with schizophrenia. Am J Psychiatry 2000; 157: 1167-9.

5 McEvoy JP, Johnson J, Perkins D, Lieberman JA, Hamer RM, Keefe RS, et al. Insight in first-episode psychosis. Psychol Med 2006; 36: 1385-93.

6 Takai A, Uematsu M, Ueki $\mathrm{H}$, Sone $\mathrm{K}$, Kaiya $\mathrm{H}$. Insight and its related factors in chronic-schizophrenic patients - a preliminary study. Euro J Psychiatry 1992; 6: 159-70.

7 Laroi F, Fannemel M, Ronneberg U, Flekkoy K, Opjordsmoen S, Dullerud R, et al. Unawareness of illness in chronic schizophrenia and its relationship to structural brain measures and neuropsychological tests. Psychiatry Res 2000; 100: 49-58.

8 Flashman LA, McAllister TW, Johnson SC, Rick JH, Green RL, Saykin AJ. Specific frontal lobe subregions correlated with unawareness of illness in schizophrenia: a preliminary study. J Neuropsychiatry Clin Neurosci 2001; 13: 255-7.

9 Sapara A, Cooke M, Fannon D, Francis A, Buchanan RW, Anilkumar AP, et al. Prefrontal cortex and insight in schizophrenia: a volumetric MRI study. Schizophr Res 2007; 89: 22-34.

10 Haa T, Youna T, Haa K, Rhoc K, Leed J, Kimd I, et al. Grey matter abnormalities in paranoid schizophrenia and their clinical correlations. Psychiatry Res: Neuroimaging 2004; 132: 251-60.

11 Cooke MA, Fannon D, Kulpers E, Peters E, Williams SC, Kumari V. Neurological basis of poor insight in psychosis: a voxel-based MRI study. Schizophr Res 2008; 103: 40-51. 
12 Bassitt D, Neto M, de Castro C, Busatto G. Insight and regional brain volumes in schizophrenia. Eur Arch Psychiatry Clin Neurosci 2006; 257: 58-62.

13 Rossell SL, Coakes J, Shapleske J, Woodruff PW, David AS. Insight: its relationship with cognitive function, brain volume and symptoms in schizophrenia. Psychol Med 2003; 33: 111-9.

14 David A, van Os J, Jones P, Harvey I, Foerster A, Fahy T. Insight and psychotic illness. Cross-sectional and longitudinal associations. Br J Psychiatry 1995; 167: 621-8.

15 David AS. Insight and psychosis. Br J Psychiatry 1990; 156: 798-808.

16 Morgan C, Dazzan P, Morgan K, Jones P, Harrison G, Leff J, et al. First episode psychosis and ethnicity: initial findings from the AESOP study. World Psychiatry 2006; 5: 40-6.

17 World Health Organization. The ICD-10 Classification of Mental and Behavioural Disorders. WHO, 1992.

18 World Health Organization. Schedules for Clinical Assessment in Neuropsychiatry (SCAN 2.0). WHO, 1994

19 Bebbington P, Nayani T. The Psychosis Screening Questionnaire. Int J Methods Psychiatric Res 1995; 5: 11-9.

20 Nelson H, Willison J. National Adult Reading Test (Part II) Test Manual. nferNelson, 1991.

21 Morgan KD, Dazzan P, Orr KG, Hutchinson G, Chitnis X, Suckling J, et al. Grey matter abnormalities in first-episode schizophrenia and affective psychosis. Br J Psychiatry 2007; 191 (suppl 51): s111-6.

22 Wing JK SE. The PSE-ID-CATEGO System: Supplementary Manual. Medical Research Council, 1978.

23 Kemp R, David A. Insight and compliance. In Treatment Compliance and the Therapeutic Alliance (ed B Blackwell): 61-84. Wisconsin, 1997.

24 David AS, Morgan KD, Mallett RM, Leff J, Murray R. Insight: unitary or multidimensional phenomenon? Schizophr Res 2003; 60: 14.

25 Weschsler D. The Wechsler Adult Intelligence Scale - Revised. The Psychological Corporation, 1981.

26 Ravens J. Coloured Progressive Matrices: Sets A, Ab, B. Oxford Psychologists Press, 1947.

27 Rey A. L'examen Clinique en Psychologie. [Clinical Examination in Psychology.] Presses Universitaires de France, 1964.

28 Weschsler D. Wechsler Memory Scale Revised. Psychological Corporation, 1987.

29 Gold J, Carpenter C, Randolph C, Goldberg T, Weinberger D. Auditory working memory and Wisconsin Card Sorting Test performance in schizophrenia. Gen Psychiatry 1997; 54: 159-65.

30 Yeudall L, Fromm D, Reddon J, Stefanyk W. Normative data stratified by age and sex for 12 neuropsychological tests. J Clin Psychol 1986; 42: 918-46.
31 Reitan R. Validity of the Trail Making Test as an indicator of brain damage. Percept Mot Skills 1958; 8: 271-6.

32 Bullmore ET, Suckling J, Overmeyer S, Rabe-Hesketh S, Taylor E, Brammer MJ. Global, voxel, and cluster tests, by theory and permutation, for a difference between two groups of structural MR images of the brain. IEEE Trans Med Imaging 1999; 18: 32-42.

33 Suckling J, Sigmundsson T, Greenwood K, Bullmore ET. A modified fuzzy clustering algorithm for operator independent brain tissue classification of dual echo MR images. Magn Reson Imaging 1999; 17: 1065-76.

34 Shenton ME, Dickey CC, Frumin M, McCarley RW. A review of MRI findings in schizophrenia. Schizophr Res 2001; 49: 1-52.

35 Heinrichs RW, Zakzanis KK. Neurocognitive deficit in schizophrenia: a quantitative review of the evidence. Neuropsychol 1998; 12: 426-45.

36 Gusnard DA, Raichle ME, Raichle ME. Searching for a baseline: functional imaging and the resting human brain. Nat Rev Neurosci 2001; 2: 685-94.

37 Spence SA, Brooks DJ, Hirsch SR, Liddle PF, Meehan J, Grasby PM. A PET study of voluntary movement in schizophrenic patients experiencing passivity phenomena (delusions of alien control). Brain 1997; 120 (Pt 11): 1997-2011.

38 Berti A, Bottini G, Gandola M, Pia L, Smania N, Stracciari A, et al. Shared cortical anatomy for motor awareness and motor control. Science 2005; 309 : 488-91.

39 Northoff G, Heinzel A, de Greck M, Bermpohl F, Dobrowolny H, Panksepp J. Self-referential processing in our brain-a meta-analysis of imaging studies on the self. Neuroimage 2006; 31: 440-57.

40 Ries ML, Jabbar BM, Schmitz TW, Trivedi MA, Gleason CE, Carlsson CM, et al. Anosognosia in mild cognitive impairment: relationship to activation of cortical midline structures involved in self-appraisal. $J$ Int Neuropsychol Soc 2007; 13: 450-61.

41 Shergill SS, Bullmore ET, Brammer MJ, Williams SC, Murray RM, McGuire PK. A functional study of auditory verbal imagery. Psychol Med 2001; 31: 241-53.

42 Blakemore SJ, Rees G, Frith CD. How do we predict the consequences of our actions? A functional imaging study. Neuropsychologia 1998; 36: 521-9.

43 Barta PE, Pearlson GD, Powers RE, Richards SS, Tune LE. Auditory hallucinations and smaller superior temporal gyral volume in schizophrenia. Am J Psychiatry 1990; 147: 1457-62.

44 Shergill SS, Cameron LA, Brammer MJ, Williams SC, Murray RM, McGuire PK. Modality specific neural correlates of auditory and somatic hallucinations. J Neurol Neurosurg Psychiatry 2001; 71: 688-90.

45 McGlynn SM, Schacter DL. Unawareness of deficits in neuropsychological syndromes. J Clin Exp Neuropsychol 1989; 11: 143-205. 